\title{
BIASMAP - Developing a Visual Typology and Interface to Explore and Understand Decision-Making Errors in Management
}

\author{
Martin Eppler and Christian Muntwiler ${ }^{(\bowtie)}$ \\ Institute for Media and Communication Management, University of St. Gallen, \\ Blumenbergplatz 9, 9000 St. Gallen, Switzerland \\ christian.muntwiler@unisg.ch
}

\begin{abstract}
In this paper we develop a novel interactive and highly visual interface to make current research about cognitive biases in strategic decision-making processes widely available to non-experts in management, administration, and engineering. Cognitive biases play a major role in the process of strategic decisionmaking. Thus, the recognition, compilation, and understanding of these biases is crucial to develop approaches to debias decisions. The literature on cognitive biases is highly fragmented and includes various research fields. This makes it difficult to gain an overview or find relevant biases quickly. To structure this knowledge, we have developed a typology of cognitive biases based on existing classificatory frameworks and an integrative literature analysis. This led to a two-dimensional typology combining the psychological view on cognitive biases with a decision process-oriented perspective. As a result, knowledge about 187 cognitive biases that affects decision-making is presented in a practice-oriented structure (viewable at bias.visual-literacy.org).
\end{abstract}

Keywords: Visual interface $\cdot$ Cognitive biases $\cdot$ Strategic decision-making · Typology $\cdot$ Knowledge map

\section{Introduction}

Cognitive biases are systematic, non-random, thus predictable deviations from rationality in judgement or decision-making [1-5]. Their impact on strategic decision-making has been recognized over the last four decades by many researchers [2, 6-14]. They follow a "Meliorist" position with the assumption that by recognizing these biases, human reasoning can be improved. This is in contrast to a "Panglossian" or "Apologist" position, where little motivation and potential is recognized for correction [15]. Thus, the facilitation of a strategic decision process plays a vital role to "assist the self-organizing process of the episode, helping to establish temporary routines that are suited to the purpose of strategic reflection" [16], as "good process, in short, isn't just good hygiene; it's good business" [17]. To improve reasoning, strategists need to "(1) identify when they have acted inconsistently [thus, when they were biased] ..., (2) explore the conditions that created this [what led to this specific bias], and (3) change these conditions to generate 
better results [intervention]" [18]. This leads to the sequence recognition - diagnosis - intervention [19]. As the literature on cognitive biases is highly fragmented and from different research areas and streams, this article follows the call for mapping cognitive biases in strategic decision-making [20] to recognize the potential cognitive limitations of decision makers in the strategy process $[6,9]$.

A knowledge visualization in this context is a visual representation to improve management [21]. It captures and depicts knowledge, supports the facilitation of processes, makes knowledge communicable and supports new discoveries [22]. The goal of this article is to develop a knowledge map of cognitive biases in strategic decision-making. This provides a basis to later design intervention mechanisms and systems allowing to reduce the influence of cognitive biases (debiasing) [23, 24] and therefore making strategic decision-making more efficient [2].

In a first step we structure the knowledge on cognitive biases in a typology that helps to identify when a bias might occur and why these cognitive biases interfere with a decision. In a second step, known cognitive biases are placed within the map and its features are explained.

\section{A Typology of Cognitive Biases}

As the research area of cognitive biases has seen a lot of attention during the last 50 years, there are already many different classificatory frameworks following different approaches. In terms of scope, we have analyzed existing frameworks and if they provide consistent and unique, mutually exclusive, and complete categories [25] to support the recognition and diagnosis of cognitive biases in strategic decision-making processes. Following the recommendation of Snyder [26] for studies which include different disciplines and a broad topic with different conceptualizations, we have conducted an integrative literature review of existing classificatory frameworks. This also serves the aim to later synthesize existing knowledge to "enable new theoretical frameworks and perspectives to emerge" [26]. We have summarized the review in a conceptual framework to "weave the streams of research together" [27].

\subsection{Analysis of Existing Classificatory Frameworks}

The systematic search provided 24 existing classificatory frameworks for cognitive biases in decision-making. By analyzing the source of publication, the research background of the authors, the classification approach, and their main goal for the classification two different approaches to structure cognitive biases were identified: exploratory approaches and explanatory approaches.

One approach how researcher classified cognitive biases is exploratory, focusing on the recognition of cognitive biases in decision-making processes. On this basis, cognitive biases were clustered using different procedures such as card sorting [28, 29], perceived similarities [5, 30, 31], and a generic structure of decision-making processes [6, 32-34].

The second kind of approaches focuses on a more diagnostic perspective: the explanation of "why" cognitive processes in human judgment, choice and decision-making lead to a systematic, involuntarily, and hard to avoid deviation in perception, judgment 
and memory from the normative reality [35]. Dimara et al. [29] identify these classifications as "explanatory". These diagnostic frameworks can be structured into explanations based on conceptual cognitive processes [35, 36], heuristics [4, 37-39], general thinking mechanisms and contaminations of the human mind [40-43], the satisfaction of motivational end states of people making decisions [44], an evolutionary perspective [45, 46], the concept of formal autonomy [47], or simply by using quantitative methods [48].

For successful corrective debiasing in strategic decision-making both perspectives are needed $[18,49]$. But this is not provided by existing classificatory frameworks as they each focus on only one perspective. Thus, there is a need for a combination of both perspectives, the when (within the process of strategic decision making) and the why (the psychological background of a cognitive bias), this may help to find the right "cure" to mitigate.

\subsection{Developing a New Typology of Cognitive Biases in Strategic Decision-Making Processes}

In contrast to an empirical taxonomy, a typology is based on conceptually developed ideal types [50], "to yield conceptually clear-cut types or classes" [51]. To develop a typology a theoretical "a priori" conceptualization of classes is followed by the placement of classified items into these conceptualized classes [52]. This conceptual classification is based on few dimensions [51] which are "theoretically derived, and more or less intuitively categorized, qualities of observed phenomena" [52]. The "central classification theme (such as cui bono)" [52] in our case is to help a strategist recognize when and why the process of strategic decision-making is flawed by cognitive biases.

Creation of Categories from the Exploratory Perspective. The general requirements for classificatory principles in a typology are consistency and uniqueness, mutually exclusiveness, and completeness [25], that they are simple and parsimonious, easily understandable and natural [53] - and theoretically derived [52].

To support recognition of cognitive biases the "natural" steps or phases within the process of decision-making may be of help. The classificatory frameworks of Einhorn and Hogarth [33, 54] and Schwenk [6] are both based on this perspective. They are easier to understand and more natural from the perspective of a decision maker or facilitator than perceived similarity, which is "incomplete, and has considerable overlap" [30].

Based on the analysis of further general process models of (strategic) decisionmaking, five generic phases can be extracted from theory, the same structure is also supported by Acciarini et al. [55]: information acquisition, option generation, evaluation \& choice, planning \& implementation, and review \& feedback.

The five generic phases of strategic decision-making provide five theoretically derived categories for the first classificatory dimension "recognition" as classification criteria for the theoretical placement.

Creation of Categories from the Explanatory Perspective. For the development of categories for the second perspective, the explanatory one, the existing classification criteria focusing on cognitive processes and perceived relationships between the biases face two disadvantages. First, "taxonomies that focus on the mechanisms behind the 
origin of biases (e.g. heuristics) are often not exhaustive when it comes to include all biases, but rather give examples of biases from specific reasoning processes" [29] - thus "the spectrum of biases considered was relatively narrow" [44]. Second, for a strategist and facilitator the underlying cognitive processes and relationships in the individuals are hard to detect, hurting the principles of simple and parsimonious, easily understandable and natural [53]. This leads to the conclusion that the categories that show how cognitive biases help "to satisfy one of the three motivational end states" of individual (simplification biases, verification biases, and regulation biases) [44] can give an explanation for the why, the diagnosis, of a particular cognitive bias and are easy to communicate. The concept behind this perspective is "that biases are consequences, or side effects, of individual's attempts to satisfy basic motivations. Given the existence of guiding motivational forces, certain dispositions can ultimately lead to biased perceptions, judgements and responses", and therefore this approach classifies "biases within the same category if they arise in the process of aiming for the same motivational goal" [both 44]. This concept is also supported by the findings of Ceschi et al. [48].

Theoretically Developed Ideal Types of Cognitive Biases in Strategic DecisionMaking Processes. The combination of the classificatory principles from the exploratory, decision process-oriented perspective and the explanatory, psychological perspective leads to 15 ideal types of cognitive biases in strategic decision-making processes ensued (overview see bias.visual-literacy.org).

\section{A Knowledge Map of Cognitive Biases}

To develop a knowledge map for cognitive biases, known biases were at first theoretically placed within the ideal types of the typology, the sections of the map. For the development and design of this knowledge map, we utilized the main principles of the field of knowledge visualization, namely: visual variety, visual unfreezing, visual discovery, visual playfulness, and visual guidance [22].

\subsection{Theoretical Placement - Organizing the Knowledge}

The last step in the creation of typology according to Rich [52] is the theoretical placement of existing items into the structure of the typology. The rules to include cognitive biases in this typology were: recognized as a cognitive bias by the academic community, occurring in one of the 5 identified phases of decision-making, and relatable to one of the three psychological-based categories (simplification, verification, regulation).

As there is currently no existing research canon of cognitive biases, the theoretical placement started with the list of 154 cognitive biases developed by Dimara et al. [29] based on Wikipedia and verified with scientific sources. In a second iteration, we cross checked with other existing classifications of cognitive biases. This led to the addition of further biases neglected by other sources. The result is 187 identified cognitive biases in strategic decision-making. To classify the cognitive biases, we carried out a textual analysis using the same sources provided by the existing classificatory frameworks. If 
these articles were not extensive enough for the theoretical placement into the ideal types, additional scientific papers with more descriptive details had been added.

As not all biases are yet researched in the same depth concerning the psychological and motivational background, the theoretical placement is based on the current research status and is therefore - as new knowledge to some of the biases will be discovered - up for future amends, with the current typology serving as a "letter case for the meaningful".

\subsection{The BIASMAP Application}

To present this knowledge, a visual interface was developed with the help of five knowledge visualization principles:

1. Visual variety: The bias map combines an overview diagram connecting both axis of the typology (psychological axis, managerial axis) with a textual explanation of the biases, the theoretical background for the placement, and for some of the biases, short video sequences with a practical example.

2. Visual unfreezing: Biases can be chosen, and an individual list of biases can be extracted for further use.

3. Visual discovery: The map allows to detect new patterns, new biases and connect them to the phases of managerial and strategic decision-making.

4. Visual playfulness: Bias journeys are provided, and users can generate their own bias journeys from their experience.

5. Visual guidance: Filters for specific kind of biases, and filters for the ideal types and both axes help users to explore the knowledge on cognitive biases.

This finally led to the BIASMAP (bias.visual-literacy.org) where managers and researcher can explore 187 known cognitive biases.

\section{Conclusion and Limitations}

Our knowledge map of cognitive biases in strategic decision-making processes makes three contributions to the academic community: as a typology for future research on cognitive biases in strategic decision-making, by showing potential research gaps (ideal types without identified biases), and foremost by providing a visual representation of knowledge on cognitive biases to support the facilitation of strategic decision-making processes by easing the knowledge acquisition and understanding. By knowing and understanding what the problem is, a strategist can start to intervene correctively by using appropriate debiasing methods within the strategic decision-making process.

But there is one major limitation in the typology as basis for this visual representation: The actual placement is based on the current status of research, thus as the classified cognitive biases are researched in more detail (especially the motivational background), the present typology can become more accurate over time and biases may be rearranged within the typology. 


\section{References}

1. Blanco, F.: Cognitive bias encyclopedia of animal cognition and behavior. In: Vonk, J., Shackelford, T. (eds.) Encyclopedia of Animal Cognition and Behavior, pp. 1-7. Springer, Cham (2017)

2. Das, T.K., Teng, B.S.: Cognitive biases and strategic decision processes: an integrative perspective. J. Manag. Stud. 36, 757-778 (1999). https://doi.org/10.1111/1467-6486.00157

3. Kahneman, D., Slovic, P., Tversky, A.: Judgment Under Uncertainty: Heuristics and Biases. Cambridge University Press, Cambridge (1982)

4. Tversky, A., Kahneman, D.: Judgment under uncertainty: heuristics and biases. Science 185, 1124-1131 (1974). https://doi.org/10.1126/science.185.4157.1124

5. Arnott, D.: Cognitive biases and decision support systems development: a design science approach. Inf. Syst. J. 16, 55-78 (2006)

6. Schwenk, C.R.: Cognitive simplification processes in strategic decision-making. Strateg. Manag. J. 5, 111-128 (1984)

7. Powell, T.C., Lovallo, D., Fox, C.R.: Behavioral strategy. Strateg. Manag. J. 32, 1369-1386 (2011)

8. Hodgkinson, G.P., Clarke, I.: Exploring the cognitive significance of organizational strategizing: a dual-process framework and research agenda. Hum. Relations 60, 243-255 (2007). https://doi.org/10.1177/0018726707075297

9. Barnes, J.H.: Cognitive biases and their impact on strategic planning. Strateg. Manag. J. 5, 129-137 (1984)

10. Schwenk, C.R.: Information, cognitive biases, and commitment to a course of action. Acad. Manag. Rev. 11, 298-310 (1986)

11. Schwenk, C.R.: Strategic decision making. J. Manag. 21, 471-493 (1995)

12. Bateman, T.S., Zeithaml, C.P.: The psychological context of strategic decision: a model and convergent experimental findings. Strateg. Manag. J. 10, 59-74 (1989)

13. Simon, H.A.: Making management decisions: the role of intuition and emotion. Acad. Manag. Exec. 1, 57-64 (1987)

14. Lovallo, D., Kahneman, D.: Delusions of success. Harv. Bus. Rev. 81, 56-63 (2003)

15. Stanovich, K.E.: Who is Rational? Studies of Individual Differences in Reasoning. Lawrence Erlbaum Associates, Mahwah (1999)

16. Hendry, J., Seidl, D.: The structure and significance of strategic episodes: social systems theory and the routine practices of strategic change. J. Manag. Stud. 40, 175-196 (2003). https://doi.org/10.1111/1467-6486.00008

17. Lovallo, D., Sibony, O.: The case for behavioral strategy. McKinsey Q. 26, 30-40 (2010)

18. Schwarz, R.M.: The Skilled Facilitator. A Comprehensive Resource for Consultants, Facilitators, Coaches, and Trainers. Jossey-Bass, Hoboken (2017)

19. Westley, F., Waters, J.A.: Group facilitation skills for managers. Manag. Learn. 19, 134-143 (1988)

20. Leiblein, M.J., Reuer, J.J., Zenger, T.: What makes a decision strategic? Strateg. Sci. 3, 558-573 (2018). https://doi.org/10.1287/stsc.2018.0074

21. Eppler, M.J., Burkhard, R.A.: Visual representations in knowledge management: framework and cases. J. Knowl. Manag. 11, 112-122 (2007). https://doi.org/10.1108/136732707107 62756

22. Eppler, M.J.: What is an effective knowledge visualization? Insights from a review of seminal concepts. In: 2011 15th International Conference on Information Visualisation, pp. 349-354 (2011)

23. Hutzschenreuter, T., Kleindienst, I.: Strategy-process research: what have we learned and what is still to be explored. J. Manag. 32, 673-720 (2006). https://doi.org/10.1177/014920 6306291485 
24. Burgelman, R., Floyd, S., Laamanen, T., et al.: Strategy processes and practices: dialogues and intersections. Strateg. Manag. J. 39, 531-558 (2018). https://doi.org/10.1002/smj.2741

25. Bowker, G.C., Star, S.L.: Sorting Things Out. Classification and Its Consequences. MIT Press, Cambridge (1999)

26. Snyder, H.: Literature review as a research methodology: an overview and guidelines. J. Bus. Res. 104, 333-339 (2019). https://doi.org/10.1016/j.jbusres.2019.07.039

27. Torraco, R.J.: Writing integrative literature reviews: guidelines and examples. Hum. Resour. Dev. Rev. 4, 356-367 (2005). https://doi.org/10.1177/1534484305278283

28. Carter, C.R., Kaufmann, L., Michel, A.: Behavioral supply management: a taxonomy of judgment and decision-making biases. Int. J. Phys. Distrib. Logist. Manag. 37, 631-669 (2007). https://doi.org/10.1108/09600030710825694

29. Dimara, E., Franconeri, S., Plaisant, C., et al.: A task-based taxonomy of cognitive biases for information visualization. IEEE Trans. Vis. Comput. Graph. 26, 1413-1432 (2020). https:// doi.org/10.1109/TVCG.2018.2872577

30. McFadden, D.: Rationality for economists? J. Risk Uncertain 19, 73-105 (1999)

31. Bhandaria, G., Hassanein, K.: An agent-based debiasing framework for investment decisionsupport systems. Behav. Inf. Technol. 31, 495-507 (2012)

32. Remus, W.E., Kottemann, J.E.: Toward intelligent decision support systems: an artificially intelligent statistician. MIS Q. 10, 403-418 (1986)

33. Hogarth, R.M.: Judgement and Choice. The Psychology of Decision, 2nd edn. Wiley, Chichester (1987)

34. Klotz, L.: Cognitive biases in energy decisions during the planning, design, and construction of commercial buildings in the United States: an analytical framework and research needs. Energy Effic. 4, 271-284 (2011). https://doi.org/10.1007/s12053-010-9089-z

35. Pohl, R.F.: Cognitive Illusions: Intriguing Phenomena in Thinking, Judgment and Memory, 2nd edn. Routledge/Taylor \& Francis Group, New York (2017)

36. Keren, G.: Cognitive aids and debiasing methods: can cognitive pills cure cognitive ills? Adv. Psychol. 68, 523-552 (1990)

37. Bazerman, M.H., Moore, D.A.: Judgment in Managerial Decision Making. Wiley, Hoboken (2009)

38. Gilovich, T., Griffin, D., Kahnemann, D.: Heuristics and Biases. The Psychology of Intuitive Judgment. Cambridge University Press, Cambridge (2002)

39. Peón, D., Antelo, M., Calvo-Solvosa, A.: An inclusive taxonomy of behavioral biases. Eur. J. Gov. Econ. 6, 24-58 (2017)

40. Stanovich, K.E., West, R., Toplak, M.E.: The Rationality Quotient. Toward a Test of Rational Thinking. The MIT Press, Cambridge (2016)

41. Korteling, J.E., Brouwer, A.-M., Toet, A.: A neural network framework for cognitive bias. Front. Psychol. 9, 1-12 (2018). https://doi.org/10.3389/fpsyg.2018.01561

42. Baron, J.: Thinking and Deciding. Cambridge University Press, Cambridge (2000)

43. Wilson, T.D., Brekke, N.: Mental contamination and mental correction: unwanted influences on judgments and evaluations. Psychol. Bull. 116, 117-142 (1994). https://doi.org/10.1037/ 0033-2909.116.1.117

44. Oreg, S., Bayazit, M.: Prone to bias: development of a bias taxonomy from an individual differences perspective. Rev. Gen. Psychol. 13, 175-193 (2009). https://doi.org/10.1037/a00 15656

45. Arkes, H.R.: Costs and benefits of judgment errors: implications for debiasing. Psychol. Bull. 110, 486-498 (1991)

46. Haselton, M.G., Bryant, G.A., Wilke, A., et al.: Adaptive rationality: an evolutionary perspective on cognitive bias. Soc. Cogn. 27, 733-763 (2009)

47. Blumenthal-Barby, J.S.: Biases and heuristics in decision making and their impact on autonomy. Am. J. Bioeth. 16, 5-15 (2016) 
48. Ceschi, A., Costantini, A., Sartori, R., et al.: Dimensions of decision-making: an evidencebased classification of heuristics and biases. Pers. Individ. Dif. 146, 188-200 (2019). https:// doi.org/10.1016/j.paid.2018.07.033

49. Larrick, R.P.: Debiasing. In: Koehler, D.J., Harvey, N. (eds.) Blackwell Handbook of Judgment and Decision Making, pp. 316-337. Wiley-Blackwell, Oxford, Malden (2004)

50. Doty, D.H., Glick, W.H.: Typlogies as a unique form of theory buildings: toward improved understanding and modeling. Acad. Manag. Rev. 19, 230-251 (1994)

51. Sanchez, J.C.: The long and thorny way to an organizational taxonomy. Organ. Stud. 14, 73-92 (1993)

52. Rich, P.: The organizational taxonomy: definition and design. Acad. Manag. Rev. 17, 758-781 (1992)

53. Gregor, S.: The nature of theory in information systems. MIS Q. 30, 611-642 (2006). https:// doi.org/10.2307/25148742

54. Einhorn, H.J., Hogarth, R.M.: Behavioral decision theory: processes of judgment and choice. J. Account Res. 19, 1-31 (1981)

55. Acciarini, C., Brunetta, F., Boccardelli, P.: Cognitive biases and decision-making strategies in times of change: a systematic literature review. Manag. Decis. (2020). https://doi.org/10. 1108/MD-07-2019-1006 